Military Technical College

Kobry El-Kobbah, Cairo, Egypt

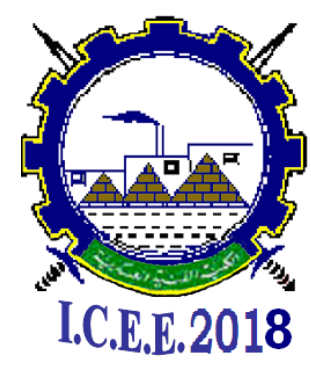

$9^{\text {th }}$ International Conference on

Chemical \& Environmental

Engineering

3-5 April 2018

\title{
SMD-4
}

\section{Biosensor-based real-time monitoring of pollutants degradation processes in water}

\author{
Georges ISTAMBOULIE, Carole CALAS-BLANCHARD, Jean-Louis MARTY, Thierry \\ NOGUER
}

\begin{abstract}
:
Biosensors have been described for many years as good substitutive or complementary tools to conventional methods for pollutants detection. In this work we present the integration of biosensors in two degradation processes for on-line, real-time monitoring of water contaminants.

Paracetamol was firstly used as a model molecule due to its wide use as pharmaceutical product. The developed biosensor was based on Tyrosinase immobilization in a polyvinylalcohol photocrosslinkable polymer. The developed tool was installed besides a photocatalytic reactor involving titanium dioxide $\left(\mathrm{TiO}_{2}\right)$ as photocatalyst. The results showed the ability of the biosensor to accurately monitor the paracetamol degradation with time. Compared with conventional HPLC analysis, the described device provides real-time information on the reaction advancement, allowing a better control of the photodegradation process.

A detoxification system of Organophosphate Agents (OP) in water was also developed based on immobilized bacterial phosphotriesterase (PTE) on activated Agarose gel via covalent coupling. Two OPs were studied, chlorpyrifos and chlorfenvinfos, due to their importance in the field of water policy. The efficiency of insecticide degradation was controlled using a highly sensitive biosensor allowing the detection of OP concentration at concentrations as low as 4 ppt.
\end{abstract}

\section{Keyword:}

Biosensor, Organophosphate Nerve Agents, Pharmaceutical Product, Water, Degradation Process

Université de Perpignan Via Domitia, Biocapteurs-Analyse-Environnement, 66860 Perpignan, France Laboratoire de Biodiversité et Biotechnologies Microbiennes, USR 3579 Sorbonne Universités (UPMC) Paris 6 et CNRS Observatoire Océanologique, 66650 Banyuls-sur-Mer, Francegeorges.istamboulie@univ-perp.fr 